\title{
Placenta praevia in Najran University hospital: incidence and risk factors
}

\author{
Sana B. Mustafa ${ }^{1}$, Abdulhadi M. Elbashir ${ }^{2 *}$, Adil Y. Waddad ${ }^{3}$, Abdelrahman M. A. Ibrahim ${ }^{4}$
}

${ }^{1}$ Department of Obstetrics and Gynecology, ${ }^{2}$ Department of Surgery, ${ }^{3}$ Department of Family Medicine Applied Medical Statistics and Demography, ${ }^{4}$ Department of Pathology, Najran University, Najran, KSA

Received: 19 March 2017

Accepted: 10 April 2017

\section{*Correspondence:}

Dr. Abdulhadi M. Elbashir,

E-mail: ahadi25@hotmail.com

Copyright: () the author(s), publisher and licensee Medip Academy. This is an open-access article distributed under the terms of the Creative Commons Attribution Non-Commercial License, which permits unrestricted non-commercial use, distribution, and reproduction in any medium, provided the original work is properly cited.

\begin{abstract}
Background: Placenta praevia is a source of drastic pregnancy, fetal and neonatal complications. There was variable incidence in the literature in different parts of the world and within the same country regions. We carried out this study to find the impact in our area and the possible risk factors for this serious obstetric problem.

Methods: This study is a cross-sectional descriptive, one-year retrospective one-year prospective study, carried out from April 2014 to April 2016. All pregnant women attended the antenatal care clinic in Najran University Hospital during the study period, were included.

Results: The incidence of placenta praevia was found to be $2.7 \%$. AMONG the study group, the most affected age group was between 20-29 years. Previous placenta praevia and previous caesarean section were the significant risk factors $\mathrm{P}=0.00$ and 0,017 repectively.

Conclusions: The incidence of placenta praevia in Najran KSA in this study was high, compared to other regions in Saudi Arabia and the majority of the international figures. Caesarean section and previous placenta praevia were the significant risk factors for placenta praevia in this study.
\end{abstract}

Keywords: Incidence, Najran, Placenta praevia, Risk

\section{INTRODUCTION}

Placenta praevia is characterized by the abnormal placenta overlying the endocervical os, and it is known as one of the most feared adverse maternal and fetalneonatal complications in obstetrics. ${ }^{1}$ Women with placenta praevia are at an increased risk of second trimester vaginal bleeding. ${ }^{2}$ Placenta praevia is a source of drastic pregnancy, fetal and neonatal complications, e.g. peripartum hysterectomy, blood transfusion, postpartum hemorrhage, and placenta accreta for the mother, prematurity and intrauterine growth restriction for the fetus and increase in neonatal mortality rates in singleton pregnancies. ${ }^{3}$

Pathophysiology of placenta praevia is uncertain. Moreover, there appears to be an association between endometrial damage and uterine scarring and subsequent placenta praevia. We have conducted this study to find out the incidence of placenta praevia in Najran University Hospital. $^{4}$

\section{METHODS}

This study is a cross-sectional descriptive, one-year retrospective and one-year prospective study, carried out from April 2014 to April 2016. All pregnant women attended the antenatal care clinic in Najran University Hospital during the study period, were included. The data was collected in a designed questionnaire after informed consent from all patients in the prospective period.

The patient's records in the retrospective period were the source of data. Abdominal Ultrasound scanning was 
routine in all patients attending our antenatal clinic. For the diagnosis of the placenta praevia, we scan our patient in the second and third trimesters. The results were analyzed using SPSS program version 16. Statistical correlations and quantification of data were done. The main characteristics of the Dependent variable and risk factors were described as (frequency and percent). Risk factors studied were Maternal Age, Parity, Previous placenta praevia, previous cesarean section, Anemia, Hypertension, Diabetes, and Multiple-pregnancy. Crosstabs' statistics and measures of association computed for risk factors. All $\mathrm{p}$ values less than 0.05 were taken as significant.

\section{RESULTS}

The total number of patients in this study was $(n=849)$ pregnant women attended the antenatal care clinic in Najran University Hospital, from April 2014 to April 2016. The age-groups distribution and the risk factors for placenta praevia are shown in (Table 1).

Table 1: Risk factors isolation (in all patients).

\begin{tabular}{|lll|}
\hline \multicolumn{1}{l}{ Count } & $\%$ \\
\hline Maternal age & & \\
\hline$<20$ & 42 & 4.9 \\
\hline $20-29$ & 439 & 51.7 \\
\hline $30-39$ & 348 & 41.0 \\
\hline$>40$ & 20 & 2.4 \\
\hline Parity & & \\
\hline 1 & 386 & 45.5 \\
\hline 2 & 200 & 23.6 \\
\hline 3 & 147 & 17.3 \\
\hline$>4$ & 116 & 13.7 \\
\hline Previous placenta & previa & \\
\hline Yes & 29 & 3.4 \\
\hline No & 817 & 96.6 \\
\hline Previous cesarean section & \\
\hline Yes & 217 & 25.6 \\
\hline No & 632 & 74.4 \\
\hline Anemia & & \\
\hline Yes & 458 & 53.9 \\
\hline No & 391 & 46.1 \\
\hline Hypertension & & \\
\hline Yes & 13 & 1.5 \\
\hline No & 836 & 98.5 \\
\hline Diabetes & 486 & 5.4 \\
\hline Yes & 804 & 94.7 \\
\hline No & \\
\hline Multiple pregnancy & \\
\hline Yes & & \\
\hline No & & \\
\hline & & \\
\hline & & \\
\hline
\end{tabular}

Twenty-three pregnant ladies were diagnosed with placenta praevia (Table 2) $(n=23)$ giving an overall incidence of $(2.7 \%)$.
Four of the twenty-three patients with placenta praevia had a major type (n-4) giving an incidence of $0.47 \%$ while $(n=19)$ minor type $2.23 \%$.

Table 2: Dependent variable placenta praevia types.

\begin{tabular}{|lll|}
\hline Type of placenta previa & Count & $\%$ \\
\hline No placenta previa & 826 & 97.3 \\
\hline Major & 4 & .5 \\
\hline Minor & 19 & 2.2 \\
\hline
\end{tabular}

Risk factors quantitative (Table-3) measurements revealed fifteen $(n=15)$ patient with placenta praevia in the age group 20-29 years. Eight $(n=8)$ in para. $I,(n=8)$ para II $(n=3)$ para. III, $(n=4)$ in para. IV.

Table 3: Risk factors among the 23 diagnosed placenta praevia.

\begin{tabular}{|c|c|c|}
\hline & Count & $\%$ \\
\hline \multicolumn{3}{|c|}{ Maternal age } \\
\hline$<20$ & 1 & 4.3 \\
\hline $20-29$ & 15 & 65.2 \\
\hline $30-39$ & 7 & 30.4 \\
\hline$>40$ & 0 & 0.0 \\
\hline \multicolumn{3}{|c|}{ Ethnicity } \\
\hline White & 6 & 26.1 \\
\hline Black & 17 & 73.9 \\
\hline \multicolumn{3}{|l|}{ Parity } \\
\hline 1 & 8 & 34.8 \\
\hline 2 & 8 & 34.8 \\
\hline 3 & 3 & 13 \\
\hline$>4$ & 4 & 17.4 \\
\hline \multicolumn{3}{|c|}{ Previous placenta previa } \\
\hline Yes & 17 & 37.9 \\
\hline No & 6 & 26.1 \\
\hline \multicolumn{3}{|c|}{ Previous cesarean section } \\
\hline Yes & 13 & 56.5 \\
\hline No & 10 & 43.5 \\
\hline \multicolumn{3}{|c|}{ Anemia } \\
\hline Yes & 16 & 69.6 \\
\hline No & 7 & 30.4 \\
\hline \multicolumn{3}{|c|}{ Hypertension } \\
\hline Yes & 23 & 100 \\
\hline No & 0 & 0.0 \\
\hline \multicolumn{3}{|c|}{ Diabetes } \\
\hline Yes & 23 & 100 \\
\hline No & 0 & 0.0 \\
\hline \multicolumn{3}{|c|}{ Multiple pregnancy } \\
\hline Yes & 3 & 13 \\
\hline No & 20 & 87 \\
\hline
\end{tabular}

Seventeen $(n=17)$ of the placenta praevia patient had previous placenta praevia $(\mathrm{P}=0.00)$. Thirteen $(\mathrm{n}=13)$ of placenta praevia were in patient with previous caesarean section, out of 217 patients with previous Caesarian section this was found to be a significant association $(\mathrm{P}=$ $0.017)$. Sixteen $(n=16)$ with anaemia $(P=0.304)$. None of the patients with placenta praevia in our study was 
diabetic or hypertensive $(n=0)$. Three $(n=3)$ with multiple-pregnancy $(\mathrm{P}=0.714)$.

\section{DISCUSSION}

The overall incidence of placenta praevia is $0.2-0.5 \%$ in western studies. ${ }^{5,6}$ In our study, the incidence is $2.7 \%$ which is relatively higher than most of the reported incidence world-Wide. Variation in placenta praevia incidence was reported by other investigators, figures in Asian countries were $3.63 \%$ in Iran and $3.5 \%$ in Pakistan were reported. ${ }^{7,8}$ Although our figure of $2.7 \%$ incidence of place praevia appears to be high, it is nearly identical to University of North Carolina Hospital 2.8\% and a Nigerian finding of $2.6 \%$ from Havana Specialist Hospital Lagos. Hospital figures appear to be higher. ${ }^{9,10}$

Studies from different regions in Kingdom of Saudi Arabia reported variation in the incidence of placenta praevia between the areas $0.73 \%$ Abha region, $1.19 \%$ Taif region and $0.41 \%$ Western Saudi Arabia. ${ }^{11-13}$ In our study was 2.7. The variations in the figures between the same country regions are consistent with Dazhi Fan et al, findings from China. They reported an incidence of placenta praevia of $1.2 \%$ from north east, $1.01 \%$ north, $1.1 \%$ north west, $1.15 \%$ central China, $0.93 \%$ east, $1.42 \%$ south and $2.01 \%$ south west. ${ }^{14}$ Cresswell JA et al In a systematic review and meta-analysis found a very high level of heterogeneity and regional variations in the incidence of placenta praevia; the highest was in the Asian countries. ${ }^{15}$ This finding is supportive for our finding which was different from finding in other regions of the world and nearly similar to others. There may be undiscovered factors that lead to this variation which requires further studies.

The exact aetiology of placenta praevia is unknown, and the condition may be multifactorial and is postulated to be related to many risk factors of which uterine scarring by Caesarean section is a major one. ${ }^{16}$ In our study, the association of placenta praevia with previous caesarean section was found to be significant $\mathrm{p}$-value (0.017). Our results are consistent with (RCOG Green-top Guideline No. 27) as it states the probability of a pregnancy been complicated by placenta praevia and placenta accreta increases dramatically with the number of prior cesareans a woman has had. ${ }^{17}$ When the history of placenta praevia and caesarean section were combined and tested together in our study group, the p-value became (0.00) for the occurrence of placenta praevia which increases the significance of the finding. History of previous placenta praevia, previous caesarean section increases the risk of development of placenta praevia. ${ }^{18-21}$

The majority $(65.2 \%)$ of the patients with placenta praevia in the study were in the age group 20-29 years. In contradistinction to the findings of Silver $\mathrm{R}$ et al. who found women of 30years of age or older, were more than twice as likely to have pregnancies complicated by placenta praevia as compared with those who were 20-29 years of age. ${ }^{22}$ Younger age for marriage in our study group may explain this variation. In our study patients, the age-group results had similarity with the Nigerian findings and almost matched with Tamil Nadu, India reported age group. ${ }^{3,23}$

However, a Chinese meta-analysis suggested a reduced risk for Pregnancy Induced Hypertension in women with placenta praevia, none of our patients in this study had a hypertensive disorder of pregnancy. ${ }^{24}$ We cannot withdraw a conclusion that placenta praevia is protective against hypertensive disorders of pregnancy in our study sample.

We found a high incidence of placenta praevia in Najran KSA in our study, which was different from other regions in Saudi Arabia and the majority of the international figures. Caesarean section and previous placenta praevia were the significant risk factors for placenta praevia in this study.

\section{ACKNOWLEDGEMENTS}

Authors are greatly indebted to those who made this work possible. Our gratitude to the patients who participated in the study, many thanks to the director of Najran University Hospital. Special thanks to the nursing staff for their help.

Funding: No funding sources Conflict of interest: None declared

Ethical approval: The study was approved by the Institutional Ethics Committee

\section{REFERENCES}

1. Silver RM. Abnormal placentation: placenta previa, vasa previa, and placenta accreta. Obstet Gynecol. 2015;126:654-68.

2. Rosenberg T, Pariente G, Sergienko R, Wiznitzer A, Sheiner E. Critical analysis of risk factors and outcome of placenta previa. Archives Gynecol Obstet. 2011;284(1):47-51.

3. Rajeshwari RR, Rubini M. Maternal and perinatal outcome in placenta previa-one year study in tertiary care center in Tamil Nadu, India. Int J Reprod Contracept Obstet Gynecol. 2016;5:2819-22.

4. Mastrolia SA, Baumfeld Y, Loverro G, Yohai D, Hershkovitz R, Weintraub AY. Placenta previa associated with severe bleeding leading to hospitalization and delivery: a retrospective population-based cohort study. J Matern Fetal Neonatal Med. 2016;29:3467-71.

5. Cieminski A, Długołecki F. Relationship between placenta previa and maternal age, parity, and prior caesarean deliveries. Ginekol Pol. 2005;76(4):284-9.

6. Tuzovic L, Djelmis J, Ilijic M. Obstetric risk factors associated with placenta previa development: casecontrol study. Croat Med J. 2003;44(6):728-33. 
7. Nankali A, Keshavarzi F, Shajari A, Daeichin S. Frequency of placenta previa and maternal morbidity associated with previous cesarean delivery. Open $\mathbf{J}$ Obstet Gynecol. 2014;4(14):903.

8. Nasreen F. Incidence, Causes and outcome of placenta previa. J Postgraduate Medical Institute (Peshawar-Pakistan). 2003;17(1).

9. Eichelberger KY, Haeri S, Kessler DC, Swartz A, Herring A, Wolfe HM. Placenta previa in the second trimester: sonographic and clinical factors associated with its resolution. Am J Perinatol. 2011;28(09):73540 .

10. Burodo AT, Shehu CE. Placenta praevia at Usmanu Danfodiyo University Teaching Hospital, Sokoto: A 5-year review. Sahel Medical Journal. 2013;16(2):56.

11. Bahar A, Abusham A, Eskandar M, obande A, Alsunaidi M. Risk factors and pregnancyoutcome in different types of placenta previa. J Obstet Gynaecol Can. 2009;31:126-31.

12. Arain FR, Aref Al Bizrah N, Aziz A, Jawad A, Tarem D. Incidence of placenta previa, management and maternal outcome in region of Taif. KSA. IOSRJDMS. 2016;15(10):122-6.

13. Abduljabbar HS, Bahkali NM, Al-Basri SF, Al Hachim E, Shoudary IH, Dause WR et al. Placenta previa: A 13 years experience at a tertiary care center in Western Saudi Arabia. Saudi Med J. 2016;37(7):762.

14. Fan D, Wu S, Wang W, Xin L, Tian G, Liu L. Prevalence of placenta previa among deliveries in Mainland China A PRISMA-compliant systematic review and meta-analysis. Medicine (Baltimore). 2016;95(40):e5107.

15. Cresswell JA, Ronsmans C, Calvert C, Filippi V. Prevalence of placenta praevia by world region: a systematic review and meta-analysis. Trop Med Int Health. 2013;18(6):712-24.

16. Marshall NE, Fu R, Guise JM. Impact of multiple cesarean deliveries on maternal morbidity: a systematic review. Am J Obstet Gynecol. 2011;205(3):262-e1.

17. Green-top Guideline No. 27. Placenta praevia, placenta praevia accreta, and vasa praevia: diagnosis and management. London. RCOG. 2011;1-26.

18. Hershkowitz R, Fraser D, Mazor M, Leiberman JR. One or multiple previous cesarean sections are associated with similar increased frequency of placenta previa. European J Obstet Gynecol Reproduc Biol. 1995;62(2):185-8.

19. Placenta previa. March of Dimes. Available from http://www.marchofdimes.com/pregnancy/placentaprevia.aspx. Accessed January 27,2014.

20. Gielchinsky Y, Rojansky N, Fasouliotis SJ, Ezra Y. Placenta accreta-summary of 10 years: a survey of 310 cases. Placenta. 2002;23:210-4.

21. Silver R, Landon M, Rouse D, Leveno KJ, Spong CY, Thom EA et al. Maternal morbidity associated with multiple repeat cesarean deliveries. Obstet Gynecol. 2006;107:1226-32.

22. Williams MA, Mittendorf R. Increasing maternal age as a determinant of placenta previa. More important than increasing parity? J Reproduc Med. 1993;38(6):425-8.

23. Burodo AT, Shehu CE. Placenta praevia at Usmanu Danfodiyo University Teaching Hospital, Sokoto: A 5-year review. Sahel Med J. 2013;16(2):56.

24. Yin XA, Liu YS. Association between placenta previa and risk of hypertensive disorders of pregnancy: a meta-analysis based on seven cohort studies. European Rev Med Pharmacol Sci. 2015;19:2146-52.

Cite this article as: Mustafa SB, Elbashir AM, Waddad AY, Ibrahim AMA. Placenta praevia in Najran University hospital: incidence and risk factors. Int J Reprod Contracept Obstet Gynecol 2017;6:1758-61. 